\title{
Cytokine-based Biologic Agent IRX-2
}

National Cancer Institute

\section{Source}

National Cancer Institute. Cytokine-based Biologic Agent IRX-2. NCI Thesaurus. Code C53396.

A cell-free mixture comprised of a variety of naturally-derived cytokines obtained from normal, unrelated donor lymphocytes with potential immunostimulatory activity. The cytokines in IRX-2, including interleukin (IL)-1, -2, -6, -8, -10,-12, tumor necrosis factor alpha (TNF-a), interferon-gamma (IFN-g) and colony stimulating factors (CSFs), play vital roles in regulating cellular immunity and may synergistically stimulate a cellular immune response against tumor cells. 